\title{
TECENDO MEMÓRIAS E AUSÊNCIAS: AUTOBIOGRAFIA COMO MATÉRIA DA ARTE
}

\section{WEAVING MEMORIES AND ABSENCES: SELF- BIOGRAPHY AS ART'S MATERIAL}

Bernadette Maria Panek ${ }^{1}$ Rita Isabel $\mathrm{Vaz}^{2}$ 


\section{Resumo}

Este artigo buscou compreender a autobiografia como matéria da arte tendo como referência os artistas Louise Bourgeois, Frida Kahlo e José Leonilson. Bourgeois transforma suas memórias, perdas e traumas em arte. Kahlo dribla a dor, expressa sua paixão pela vida. Leonilson enfrenta a proximidade da morte. Encontrei conexão com estes artistas cujas vidas e obras se confundem. O procedimento metodológico parte da investigação teórica e do trabalho prático em relação dialética ao longo de todo o processo. De Gaston Bachelard, interessa o conceito de casa/corpo, como lugar da dimensão onírica da recordação. Philippe Lejeune discute autobiografia e a escrita de diário com a função de conservar a memória. E Georges Didi-Huberman trata a ausência como presença, vestígio, e a pele como lugar dos sinais tanto do envelhecimento/memória quanto do desejo/toque. Resultaram desse processo três obras que se conectam aos artistas elencados e aos conceitos trazidos pelos teóricos, e evidenciam o uso da memória, da autobiografia e das ausências como expressão singular.

Palavras-chave: Memórias, Ausências, Autobiografia, Arte.

\section{Abstract}

This article searched for the comprehension of self-biography as art's material. The reference artists were Louise Bourgeois, Frida Kahlo and José Leonilson. Bourgeois transforms her memories, loses and traumas in art. Kahlo mislead the pain, expresses her passion for life. Leonilson faces the proximity of death. I've found connections with those artists whose lives and works gets mixed. The methodological procedure comes from theoretical investigation and from practical work in relation with the dialectic during the whole process. From Gaston Bachelard, concern the concept of house/body, as place of the dreamlike dimension of memory. Philippe Lejeune discusses self-biography and the writing diary with the function of preserving memory. Georges Didi-Huberman talks about the absence as presence, trace, and the skin as place of signs of both aging/ memory and of desire/touch. The result of this process were three works that connect with the artists listed and with the concepts brought by the theorists, and show the use of memory, self-biography and the absences as singular expressions.

Keywords: Memories, Absences, Self-biography, Art.

ISSN: 2175-2346

1bernapanek8@gmail.com 


\section{...Os escafandristas virão \\ Explorar sua casa \\ Seu quarto, suas coisas \\ Sua alma, desvãos Sábios em vão \\ Tentarão decifrar \\ $\mathrm{O}$ eco de antigas palavras \\ Fragmentos de cartas, poemas \\ Mentiras, retratos \\ Vestígios de estranha civilização \\ (HOLLANDA, 1993)}

\section{Introdução}

Este artigo tem o propósito de demonstrar o percurso de uma pesquisa em poéticas visuais. Envolve a construção de obras autorais, articuladas à produção de artistas de referência (Louise Bourgeois, Frida Kahlo e José Leonilson), e dos teóricos que utilizam os conceitos de autobiografia, memórias e ausências (Gaston Bachelard, Georges Didi-Huberman, Philippe Lejeune). Neste processo, a construção das obras e do texto estão intrinsecamente ligados e acontecem de forma simultânea. O processo de criação permeia toda a construção da pesquisa teórica, e ambos estão em permanente diálogo. Houve uma escolha pela construção narrativa na primeira pessoa, por tratar-se de uma pesquisa em poéticas, como assinala Sandra Rey:

É preciso lembrar que toda obra de arte é uma resposta singular a um estímulo. Porque, ao contrário da ciência, que necessita de comprovação e avança em bloco, consolidando ou refutando teorias através da reprodução de experiências em laboratório, é próprio da arte em geral e da arte contemporânea em particular propor e apresentar um ponto de vista diferenciado, ou uma visão de mundo particular, através da constituição de linguagens. (REY, 2002, p. 128)

Ao longo deste artigo, construo uma narrativa que discute os conceitos de autobiografia, memórias e ausências, passando pelas obras dos artistas de referência e dos teóricos escolhidos. Relato inicialmente a maneira singular que estabeleço com o mundo e como a trajetória particular se articula ao tema da pesquisa. No momento seguinte, dialogo com os artistas de referência a partir dos aspectos mais instigante de suas expressões poéticas. Os três artistas produziram obras autobiográficas. Para discutir esta questão, bem como memórias e ausências, trouxe para a pesquisa as contribuições teóricas de Gaston Bachelard, Georges Didi-Huberman e Philippe Lejeune. Simultaneamente, construo obras autorais que discuto ao final do artigo.

Encanta-me juntar vestígios perdidos no tempo, reunindo num mesmo espaço memórias de ausências que se fazem presentes. Trago inscritas lembranças familiares que permeiam as relações com o mundo. Da família de origem, herdei força e potência, garras e ganas de viver. Mulheres e homens plantaram suas vidas com profundas e sólidas raízes, de onde emerge vigoroso tronco, que alimenta galhos, folhas e frutos, oferece sombra e alimento, acolhe e alenta. Desvelar memórias implica revirá-las e reavivá-las, provocar reencontros de ausências, instigar o imaginário, os sonhos, o inconsciente. "Recordar: do latim re-cordis, tornar a passar pelo coração." (GALEANO, 1991, p. 11). 
No mundo submerso das lembranças, encontro ausências que permanecem presentes enquanto experiências compartilhadas ao longo da vida. Sou a décima primeira filha entre treze irmãos, meu imaginário encontra-se repleto de histórias envolvendo muitas diferenças e muitos afetos. Ao reconstruir estas memórias, surgem aos turbilhões recordações permeadas de saudades. Remexer este baú significa deparar-me com lembranças divertidas, engraçadas, trágicas, alegres, tristes, que despertam sentimentos de ternura, afeto, dor, tristeza. Na poética que construo, trago um recorte das ausências que se manifestam no imaginário como formadoras de um modo de ser e de estar no mundo. Nasci num espaço repleto de compartilhamentos, que resulta em um sentimento constante de nunca estar só. Na trama do tempo, teci perdas, dores e alegrias. Sinto que as pessoas com quem partilhamos afetos permanecem em nós enquanto memórias, e a elas podemos recorrer sempre. Este sentimento acolhe, protege, dá a sensação de força frente à fragilidade da existência.

\section{Desenvolvimento}

As artistas Louise Bourgeois (1911-2010), Frida Kahlo (1907-1954) e o artista José Leonilson (1957-1993) instigam/provocam de maneira intensa e profunda a poética que construo. Fascinante a longa e fecunda carreira de Louise Bourgeois, personagem desafiadora, agarrada à vida e à sua obra. Lida com suas perdas, suas memórias, seus traumas, suas dores, transformando emoções, conscientes ou inconscientes, em arte. Desafiadora, apaixonada e intensa a luta pela vida de Frida Kahlo, driblou a dor e a transformou em arte: em sua última obra sintetiza, em três palavras, o que perpassa toda sua existência: Viva la vida. Impactante a sensibilidade marcada pelo afeto de José Leonilson, enfrentou a AIDS num tempo em que essa síndrome era praticamente desconhecida, produziu suas obras expressando suas dores, ora apontando para a vontade de viver, ora se revoltando com a iminência da morte.

As obras que venho realizando, em determinadas particularidades, conectam-se às obras desses artistas e ao conceito de autobiografia como matéria da arte. Tomo como referência Gaston Bachelard, ampliando a ideia, por ele desenvolvida, de uma casa/corpo como construção histórica de um sujeito/artista.

A casa natal, mais que um protótipo de casa, é um corpo de sonhos. Cada um desses redutos foi um abrigo de sonhos. E o abrigo muitas vezes particularizou o sonho. Nela aprendemos hábitos de devaneio particular. A casa, o quarto, o sótão em que estivemos sozinhos, dão os quadros para um devaneio interminável, [...] existe em cada um de nós uma casa onírica, uma casa de lembrança-sonho, perdida na sombra de um além do passado verdadeiro. [ ...] Habitar oniricamente a casa natal é mais que habitá-la pela lembrança, é viver na casa desaparecida como nós sonhamos. (BACHELARD, 1988, p. 119)

A autobiografia permeia a obra dos três artistas elencados. Ao se colocarem enquanto sujeitos de um tempo histórico, transcenderam para além de suas individualidades, fizeram leituras que partiam do singular, de onde percebiam o mundo, mas que refletiam também o espaço e o tempo em que viviam. Para além da intimidade, instigam o olhar do espectador para questões que são universais, que estimulam, entre muitas outras possibilidades, a compaixão, aqui entendida como a capacidade 
de se colocar no lugar do outro, de ver com os olhos do outro, de provocar diálogo e reflexão, de tocar as vulnerabilidades das emoções profundas. Ao produzir as obras "Descansem em paz os mortos dentro de mim", "As veias abertas da América Latina", "Nós nos nós: somos feitos de muitos", "Pegadas" e "Arroubos de sonhos tecidos", e o artigo "TECENDO MEMÓRIAS, ATRAINDO OLHARES: a apropriação de padrões ornamentais e decorativos na expressão artística" ${ }^{1}$, estabeleci um estreito diálogo com o conceito de autobiografia, que trago para este artigo.

Percebo em mim e nos muitos que me habitam uma enorme vontade de viver e deixar marcas, pegadas, como uma maneira de permanecer, de não morrer. Talvez isto me instigue a recolher vestígios da história familiar, trazendo para a memória a presença destes seres no mundo, pelos afetos e objetos construídos por muitas mãos. Tratar de memórias significa transcender as dores que estão enraizadas nelas, elaborar as saudades, juntar pedaços, ressignificando-os. No delicado exercício de revisitar memórias, me reinvento, me descubro coletiva no nosso mundo, porque coletiva é também a memória.

Georges Didi-Huberman, ao descrever a impressão a partir de um molde do próprio corpo, concebe a expressão "impressão de ausência" (DIDI-HUBERMAN, 1997, p.1). Ao deixar pegadas na areia, por exemplo, deixo a impressão da ausência. Ao construir este texto e as obras decorrentes deste diálogo, moldo de forma metafórica os rostos/corpos perdidos e todas as emoções relacionadas e inscritas na minha própria pele.

\footnotetext{
A pele não seria somente o que um homem que envelhece contempla com tristeza ao observar as rugas ou sinais físicos da obra mortífera do tempo. A pele é também o subjétil de uma carícia. Campo e veículo dos sinais desejantes, ouso dizer, eles supõem, simetricamente, as versões melancólicas da impressão e a existência de versões mais histéricas, que reinventam, que erotizam o organismo a partir de uma paixão pela sua textura mesmo. Aqui a aderência não é um abafamento, mas como um beijo, e o contato não seria uma petrificação, mas dispararia movimentos virtuais dos corpos uns para os outros. (DIDI-HUBERMAN, 1997, p. 11)
}

Em Uma História da pele, Paulo Reis (2000) discorre sobre a pele enquanto lugar em que se inscreve a memória e se apresenta como possibilidade de encontro com o outro, lugar de afirmação da própria humanidade e de expressão da arte. Sinto-me cheia de ausências, como todos! Imagino tecer uma colcha com os fios da memória para com ela cobrir-me nas noites de inverno! Trabalho neste projeto as memórias que me aquecem, que estão carregadas de afetos, que provocam conforto e também saudades. Os vestígios são para mim fotografias, cartas, objetos, marcas, lembranças, saudades de um tempo longo (expressão utilizada por minha mãe para designar um tempo distante). No livro Por Parte de Pai, Bartolomeu Campos Queirós faz um relato terno de uma conversa que teve com o avô, que lhe falou sobre o tempo:

O tempo tem uma boca imensa. Com sua boca do tamanho da eternidade ele vai devorando tudo, sem piedade. O tempo não tem pena. Mastiga rios, árvores, crepúsculos. Tritura os dias, as noites, o sol, a lua, as estrelas. Ele é o dono de 1 O artigo resultante desse Projeto de Iniciação Científica: TECENDO MEMÓRIAS, ATRAINDO OLHARES: a apropriação de padrões ornamentais e decorativos
na expressão artística, foi publicado na Revista Interdisciplinar Internacional de Artes Visuais Art\&Sensorium. Vol 4. n.2. 2017 p. 322/337. 
tudo. Pacientemente ele engole todas as coisas, degustando nuvens, chuvas, terras, lavouras. Ele consome as histórias e saboreia os amores. Nada fica para depois do tempo. As madrugadas, os sonhos, as decisões, duram pouco na boca do tempo. Sua garganta traga as estações, os milênios, o ocidente, o oriente, tudo sem retorno. E nós, meu neto, marchamos em direção à boca do tempo. (QUEIRÓS, 1995, p.71)

Ao situar-me nesse tempo que tudo devora, encontro na expressão artística a possibilidade de permanência, assim como o texto poético acima descrito permaneceu para nos tocar além daquele tempo em que foi relembrado pelo autor do livro.

Na obra "Mulheres que Correm com os Lobos", Clarissa Pinkola Estés (1994) recolhe histórias, contos de fadas e lendas, relacionando-as ao feminino e interpretando-as à luz da psicologia analítica. Para ela, o arquétipo da mulher selvagem deve ser resgatado e cultivado por nós, mulheres, para nos aproximarmos de nós mesmas e não adoecermos. A primeira narrativa relatada no livro chama-se La Loba, encontrada pela autora em diferentes regiões, com pequenas variações. Trata-se da história de uma mulher idosa, que fica à espera de pessoas que se perderam; ela também é conhecida como a "Mulher dos Ossos", a "Trapeira", a "Mulher-Lobo". Seu trabalho é recolher ossos, especialmente aqueles que correm risco de se perderem. Ela acumula esses ossos em sua caverna e, quando consegue reunir um esqueleto inteiro, senta-se junto ao fogo e imagina uma canção. Então se ergue, aproxima-se do esqueleto e canta, canta com tanta energia que os ossos vão se cobrindo de carne e se transformando em lobo, que desperta, respira e se transforma em mulher que corre em direção ao horizonte (ESTÉS, 1994, p. 43-44). Para a autora, todas nós temos "ossos" guardados em nossas cavernas, e em algum momento devemos reuni-los e cantar para eles, para recuperarmos essa força ancestral, que dá sentido à nossa vida. Creio que, ao recolher vestígios da história familiar, de certa maneira estou juntando esses "ossos", e meu canto para eles será a criação de uma obra que possa fazer sentido no mundo.

A leitura de "A Destruição do Pai, A Reconstrução do Pai", de Louise Bourgeois, aflorou emoções, indagações e conteúdos oníricos acentuando questões que estavam implícitas à construção poética. Na obra Maman, de Bourgeois, em que há a representação da mãe na estrutura de uma imensa aranha, percebi a aranha como tecelã. A atividade de tecer está estreitamente ligada à minha história familiar, o que me levou a conectar com seu aspecto simbólico. Busquei na mitologia algumas definições, tanto no Dicionário dos Símbolos (CHEVALIER; GHEERBRANT, 1997) quanto nos livros de Mitologia Grega, em que aparece a aranha como tecelã, vinculada ao mito de Aracne.

Atena, deusa da Razão Superior [...] é a mestra e patrona da arte da tecelagem. Aracne, jovem lídia e simples mortal, é exímia nessa arte; por isso mesmo, ousa desafiar a divindade. [...] Atena, sentindo-se ultrajada, golpeia a jovem com sua lançadeira. Aracne resolve, então, enforcar-se; Atena poupa-lhe a vida, porém metamorfoseia-a na aranha, que para sempre há de balançar-se na ponta de seu fio. (CHEVALIER; GHEERBRANT, 1997, p. 70-71)

Em Mitologia Grega, Juanito de Souza Brandão conta a mesma história e conclui: "A aranha torna-se [...] uma artífice de teias de ilusões." (BRANDÃO, 1987, p. 28). 
Pesquisando na literatura, surpreenderam-me os muitos poemas dedicados à aranha e à sua atividade de tecedora. O poeta Walt Whitman no poema "Silenciosa aranha paciente" fala da aranha que vai jogando o fio de si mesma, relacionando-a à própria alma que mergulha no vazio, criando pontes que conectam os espaços (WHITMAN, 1964, p. 87). Fernando Pessoa, no poema "A aranha do meu destino", conta como a aranha se espalha e o apanha no seu existir (PESSOA, 1990, p. 82). Orides Fontela, no poema "Teia", constrói a ideia de teia tecida pela aranha que a torna viva, como o artista que, ao produzir sua obra, também produz a si mesmo (FONTELA, 1996, p.13). Relacionando todos estes sentidos à figura da aranha e à obra de Louise Bourgeois, projeto uma obra que ressalta metaforicamente a atividade de tecelã/protetora da aranha e a temporalidade das artesanias. Ana Maria Machado em seu livro "De Olho nas Penas", atribui à aranha a função de recolher/abrigar/relatar todas as histórias da terra. Ao narrá-las, desenrola o fio de dentro de si mesma, ao ouvi-las podemos recontá-las e acrescentar novos fios. "... eu vou ouvindo e tecendo até ficar uma teia bem completa e forte. Só com uma teia assim, bonita e resistente é que dá pra aguentar todo o peso..." (MACHADO, 1985, p. 48). Minha obra inclui esta função de guardadora e contadora de histórias.

A relação que estabeleço com a arte está intrinsecamente ligada às cores, tecidos, linhas, às técnicas dos trabalhos manuais, bem como à autobiografia, enquanto narrativa de si mesmo e do seu tempo. Nessa relação encontro alternativas expressivas. Ressalto a compreensão dos processos singulares nas obras dos artistas escolhidos, engendrando possibilidades de diálogo/aproximação/afastamento. Instiga-me a compreensão da construção histórica do artista no tempo/espaço das relações que estabelece com o mundo.

Observei nas obras dos três artistas escolhidos aspectos de colecionadores de objetos/memórias. Buscando compreender a representação dessas coleções e responder às instigantes indagações, socorreu-me o poeta Affonso Romano de Sant'Anna, no trecho final de seu poema "Objetos do morto": "[...] Não deveriam deixar pelo mundo espalhados os objetos órfãos do morto, pois eles são, na verdade, fragmentos de um corpo." (SANT'ANNA, 1992, p. 191). Assim vejo os objetos que coleciono, eles me constituem enquanto pessoa e artista, e através deles posso me expressar, são matéria de criação poética.

Nessa perspectiva, encontro conexão com a obra dos artistas Louise Bourgeois, Frida Kahlo e José Leonilson, que utilizam a autobiografia, a memória, os diários, na construção de suas poéticas, transcendendo o efeito catártico e instigando emoções que transbordam os limites da singularidade. Com a palavra, Bourgeois: "Minha infância jamais perdeu sua magia, jamais perdeu seu mistério e jamais perdeu seu drama" (BOURGEOIS; BERNADAC; OBRIST, 2000, p. 1).

\subsection{Louise Bourgeois}

A família de Louise Bourgeois restaurava tapetes. Muito cedo ela aprendeu esta atividade, que foi determinante para a realização da sua obra, segundo ela própria. Sua história familiar e os traumas de sua infância tornaram-se matéria prima para sua arte. Considero instigante a escultura Maman, (BOURGEOIS, 1999), pelo alumbramento que 
provoca. Sendo uma aranha gigante, como pode suscitar proteção e ternura? Pergunta que não importa responder, mas que modifica profundamente o olhar. A obra Ode à l'oubli (BOURGEOIS, 2002) encanta-me pela utilização de tecidos e bordados e pelo jogo poético esquecimento/recordação, que propicia os vestígios intrínsecos de autobiografia ao se materializarem neste livro/diário. The Destruction of the Father, (BOURGEOIS, 1974)² envereda pelos caminhos das memórias da artista e seus traumas, e acena para a relação arte e psicanálise. "Ao explorar a fundo seu inconsciente, a artista paradoxalmente desenvolve a capacidade de criar imagens poderosas, de significado universal" (LARRAT-SMITH, 2011, p. 14).

Bourgeois mergulha em seu inconsciente, passa pelo processo de análise durante anos de sua vida, enfrenta seus traumas, se expõe de maneira bastante corajosa para a época em que viveu, e assume esse enfrentamento em suas obras. Sua expressão singular encontra ressonância no universal porque fala dos sentimentos humanos, expressa raiva, ciúme, traumas. "Os conflitos interiores causam um recuo (para não dizer regressão) a ações simbólicas que são intensamente prazerosas. Amontoar e empilhar são atividades terapêuticas, semelhantes a manusear um cordão de contas ou desfiar o rosário." (LARRAT-SMITH, 2011, p. 15). Bourgeois mantém um diário onde relata seus sonhos, seus sentimentos, seus projetos, onde retrata sua alma. "[...] sobre lembranças 'roídas por traças' [...] Ela desapareceu num completo silêncio/ [...] Peguei minhas lembranças no colo (boas/ou más). Eu as embalei e serenei". (BOURGEOIS, in LARRAT-SMITH, 2011, p. 44).

$\mathrm{Na}$ introdução do catálogo "O retorno do desejo proibido", Philip Larrat-Smith (2011) conta que na casa de Louise Bourgeois foram encontradas mais de mil páginas soltas que são notas do seu processo de trabalho, registros de sonhos, uma espécie de diário que manteve durante toda sua existência, reunindo impressões sobre sua própria vida, sua obra, a psicanálise, a escultura, suas relações com as pessoas, com o mundo e com sua produção de arte. Bourgeois converteu em produção artística seu inconsciente, seus traumas e dramas, revelados em sua imersão no processo psicanalítico.

A literatura psicanalítica demonstra a importância das relações que estabelecemos na infância, no núcleo familiar, na determinação das nossas escolhas e da maneira de estar no mundo. A relação que estabeleci com a psicologia, tanto nos estudos quanto nos períodos de análise, resultaram num modo particular de ser. Para Sigmund Freud, o inconsciente é repleto de conteúdos reprimidos que emergem na linguagem dos sonhos (FREUD, 1973, p. 2061). A obra de Bourgeois expressa traumas infantis e conteúdos inconscientes, dizem respeito às suas vivências, às suas fantasias e desejos, explicita e oculta seus mistérios, traduzindo sua autobiografia e singularidade instigantes.

\subsection{Frida Kahlo}

Frida Kahlo produziu cerca de 55 autorretratos. Mais do que representar os ritos e hábitos mexicanos, internaliza e reafirma sua cultura. A artista combina diferentes sistemas simbólicos, confundindo-se com seus mitos, utiliza-se de um repertório do 2 As imagens das obras citadas não foram reproduzidas neste artigo em razão dos direitos autorais, porém encontram-se disponíveis nos sites mencionados nas referências. 
surrealismo, "o desenho e a escrita automáticos, a representação do onírico, a descrição de pulsões psicológicas, a atração pelo fantástico e pelo exótico" (MIYADA, In: KAHLO, 2015, p. 51). Kahlo posiciona-se politicamente na representação das tradições do seu país e naquilo que podemos vislumbrar do misterioso mundo mexicano antes das invasões hispânicas.

O diário de Frida Kahlo demonstra seus sentimentos, suas angústias, suas paixões e sua relação com o mundo. Nele parece encontrar um alento para sua solidão e suas dores. Ao mesmo tempo transborda esperança, como ela mesma escreveria: "Para mim, as asas são supérfluas, mesmo que as cortem eu voarei!" (KAHLO, 1996, p. 276). Registra seus mais intensos sentimentos e parece projetar o caminho possível para os passos dolorosos que irá trilhar. Em certo momento, relata que já havia passado por vinte e duas cirurgias, sete apenas em um ano; ao mesmo tempo, existe uma tentativa de manter-se viva através de sua arte. Kahlo, ao escrever, não está apenas falando de si e de suas dores, está unida a todos os seres que são feitos também de dores. As obras El Abrazo de Amor del Universo, la Tierra (México), Diego, Yo y el Sr. Xolotl, (KAHLO, 1949); Las dos Fridas, (KAHLO,1939); La mesa herida, (KAHLO,1940); Mis abuelos, mis padres y yo. (Árbol genealógico), (KAHLO, 1936)³, expressam ao mesmo tempo paixão e dor, a relação com a origem, os antagonismos e a preocupação com seu país, sua genealogia, a coexistência de uma autobiografia que transcende o individual e representa sua conexão com um mundo mágico do qual todos os seres fazem parte, que é ao mesmo tempo o mundo real e singular de suas angústias e indagações.

\subsection{José Leonilson}

José Leonilson, com sua obra autobiográfica, coleciona memórias. A relação do artista com o desenho, com o tempo que se esvai, com a escrita e os bordados traduzem a reflexão sobre si mesmo. O artista registra sistematicamente sua vida, escrevendo quase diariamente e gravando depoimentos em fita cassete. A linguagem do bordado explorada como desenho ganha uma "[...] abrangência simbólica, mítica..." (REIS, 1998, p. 68). As obras "Águas divididas", (LEONILSON, 1992); Empty Man, (LEONILSON, 1991); "Ninguém", (LEONILSON, 1992)4 seduzem o olhar, por conterem simultaneamente tecer, costurar, bordar e escrever memórias. Nelas, Leonilson expressa suas angústias, registra o tempo de espera e deixa suas pegadas de artista assolado pela iminência da morte.

Ao entrar em contato direto com sua obra ${ }^{5}$, percebi os estreitos laços que o artista manteve durante toda a vida com a sua família, especialmente com a mãe. Seus desenhos, bordados, projetos, coleções de linhas, tecidos, brinquedos encontram-se preservados em um espaço que reproduz o que foi o seu ateliê. Muitos dos móveis e objetos que pertenceram ao artista e constituem sua coleção foram resgatados por ele, de brechós e antiquários. Em algumas de suas obras, Leonilson utilizou-se destes objetos, em outras de suas roupas, lençois e fronhas. Os títulos que dá às suas obras

3 As imagens das obras citadas não foram reproduzidas neste artigo em razão dos direitos autorais, porém encontram-se disponíveis nos sites mencionados nas referências.

4 As imagens das obras citadas não foram reproduzidas neste artigo em razão dos direitos autorais, porém encontram-se disponíveis nos sites mencionados nas referências.

5 Em 2017, visitei o Projeto Leonilson, onde conversei longamente com Maria Lenice, irmã do artista. 
e as palavras que borda expressam metaforicamente as suas contradições, dúvidas, tristezas, amores e maneira de estar no mundo; transbordam sentimentos. A obra Voilá mon coeur, oferecida ao amigo Adriano Pedrosa, elucida a relação passional do artista/obra. Leonilson, metafórica e literalmente, oferece seu coração.

\begin{abstract}
No outono de 1989, Voilá mon coeur havia sido vendido [...] Como suporta o artista, aquele que expõe seu íntimo, tal mercantilização? "E seu coração que está lá na parede", disse ao Leo um tanto impiedosa e ingenuamente, "você o pôs a venda". Não tinha eu na época consciência de que na realidade todos os seus trabalhos, quando não metáforas de seu coração, são metonímias de seu próprio corpo. Voltei ao Rio de Janeiro e dias depois recebi, pelo correio, um pacote pelo SEDEX. Dentro dele um pequeno trabalho de ouro e cristal; no verso li: "Voilá mon coeur, il vous apartien [sic], ouro de artista é amar bastante." (PEDROSA, in LAGNADO, 1995, p. 21)
\end{abstract}

Os artistas mencionados mantiveram diários durante quase toda a vida, e neles liberavam suas mais íntimas e profundas emoções, dialogavam, questionavam, refletiam sobre suas vidas e seus tempos e como se situavam no mundo. A perspectiva apontada por Philippe Lejeune (2014), em O Pacto Autobiográfico, relaciona a autobiografia ao autorretrato. Discute questões relacionadas às cartas, enviadas e recebidas, aos diários e blogs. Considera o diário "[...] uma série de vestígios. [...] O diário é uma rede de tempo, de malhas mais ou menos cerradas... Mantemos um diário para fixar o tempo passado, que se esvanece atrás de nós, mas também por apreensão diante de nosso esvanecimento futuro." (LEJEUNE, 2014, p. 301-305). Uma escrita de alguém para si mesmo, para conservar a memória, sobreviver, desabafar, conhecer-se, deliberar, resistir, pensar.

\title{
2.4 Trabalhos autorais
}

As obras que realizo atualmente dialogam com as questões que me são instigadoras, autobiográficas e demonstram aproximações e afastamentos com as obras dos artistas de referência e com os textos dos teóricos pesquisados. A obra "Arroubos de Sonhos Tecidos" anseia mostrar a dimensão de uma teia de sonhos que se projeta do universo privado para o público. "Veias Abertas da América Latina" fala das atrocidades cometidas contra os povos originários, ao mesmo tempo que celebra a multiplicidade de nossas origens. O trabalho "Descansem em Paz os Mortos Dentro de Mim" almeja dialogar com as perdas, discutir multiplicidade e incompletude, dores e prazeres; e "Nós nos Nós" sinaliza para os muitos que habitam em nós. ${ }^{6}$

6 As fotos destas obras encontram-se disponíveis no artigo: "TECENDO MEMÓRIAS, ATRAINDO OLHARES: a apropriação de padrões ornamentais e decorativos na expressão artística", publicado na Revista Art\&Sensorium. Vol 4. n.2. 2017. A obra "Descansem em Paz os Mortos dentro de Mim, participou de uma exposição Coletiva: Nossa Mostra, na Galeria da Belas Artes, Curitiba, Paraná, no período de 01 a 08 de março de 2018. 


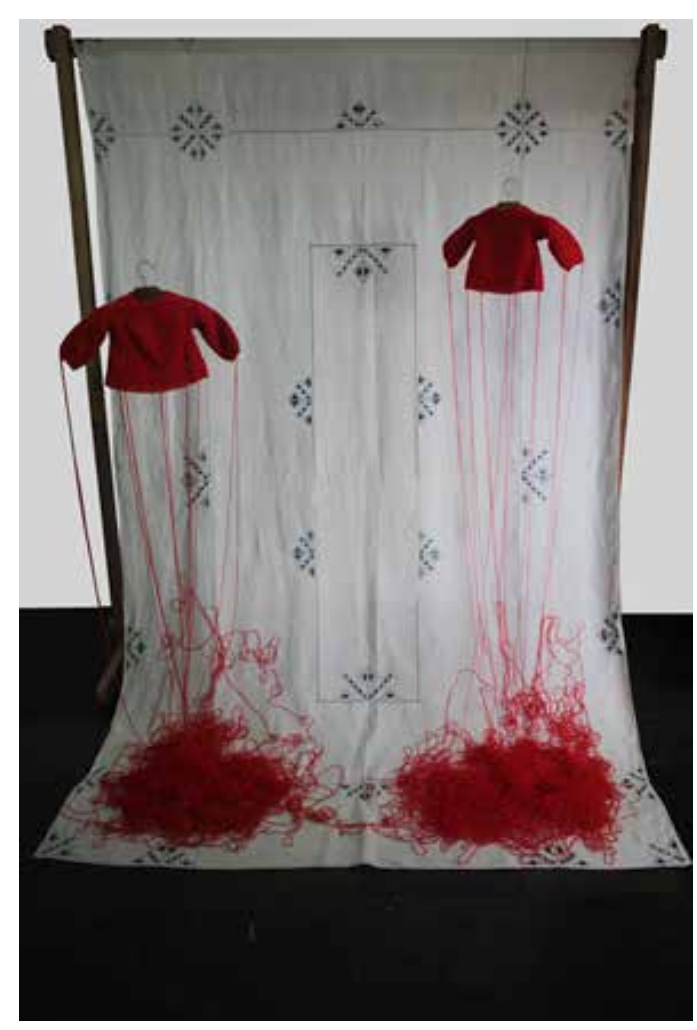

Fig. 1 - Aos Filhos que não nasceram. 2018. Objeto escultórico, suporte de madeira (imbuia), colcha de linho bordada, casaquinhos de tricô, $220 \times 175 \times 100 \mathrm{~cm}$.

Fonte: Acervo pessoal, Curitiba

A tecedura dos fios condutores desta obra perpassa a urdidura das questões autobiográficas, das memórias e ausências. "Aos filhos que não nasceram" traz a representação de abortos naturais, com a narrativa da dor. O lençol de linho, bordado à mão, puído pelo tempo, dialoga com as corroídas lembranças. De memórias fez-se o lençol, de mãos que delicadamente o bordaram. De ausências são os casaquinhos, que se desmancham em vermelho-sangue. A cor vermelha alude à tradição familiar de assim vestir os recém-nascidos para protegê-los de mau-olhado ou quebranto. $E$ alude ao sangue que escorre abruptamente. A obra reverencia e homenageia a perda, almeja driblar a morte, acenar à possibilidade de permanência. Revive sentimentos, mergulha no arquivo da memória afetiva. O suporte de imbuia, sobre o qual repousa o lençol de linho, estrutura a obra, e relaciona-se à força e cumplicidade da relação afetiva com o companheiro e os filhos que nasceram, ora ocultam, ora revelam o mistério e alegria de viver. Há uma carga de emoções intensas e profundas, marcadas na pegada ausente.

Nas obras de Frida Kahlo, Hospital Henry Ford, 1932 e Frida e o aborto, 1932, que pude ver pessoalmente, e na imensa ilustração gráfica do desenvolvimento da vida intrauterina, que se encontra fixada à parede do que foi o seu ateliê, observo o desejo da artista de ter um filho, as tentativas frustradas e a dor destas perdas. Todas essas imagens despertaram em mim emoções penosas. Tocaram em ausências que estarão sempre presentes em mim: os filhos que não nasceram. Nessa obra, mergulho na dor, distante no tempo, presente na memória. Ensimesmada nas perdas e na elaboração do luto, intento reavivar ausências, apontar para as presenças, as relações afetivas e a vida, e dialogar com tudo isso. 


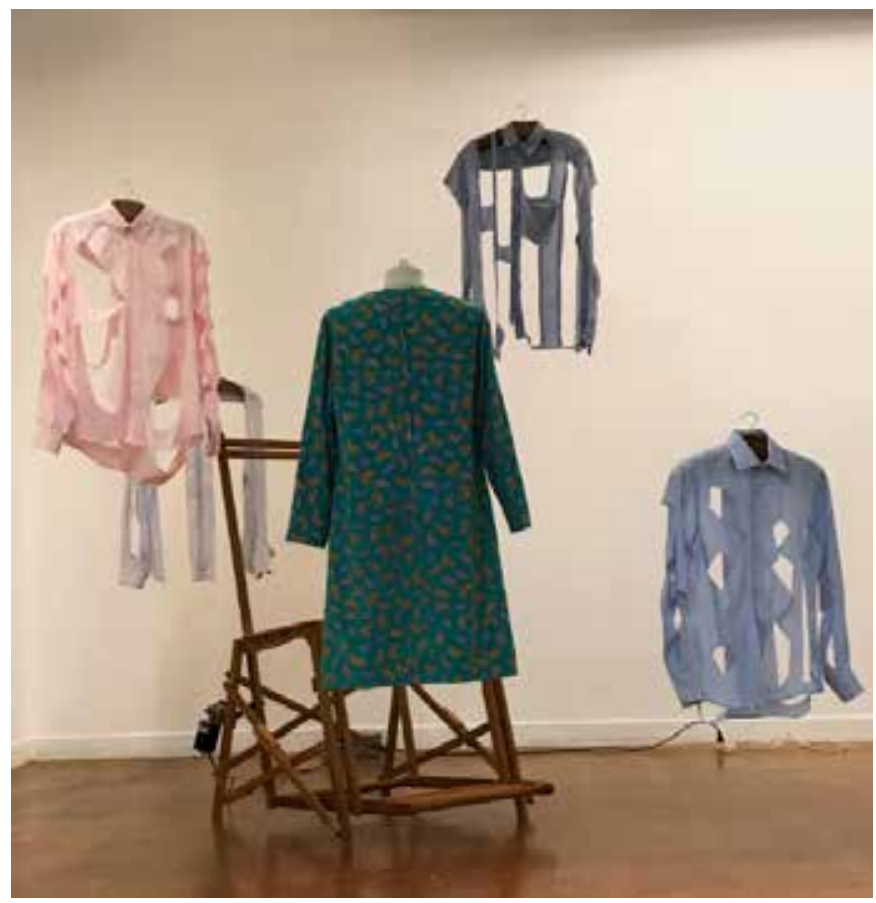

Fig. 2 - Descansem em paz os mortos dentro de mim II. 2018. Instalação, cadeira de madeira, com motor, em movimento, Vestido em manequim, camisas recortadas em cabides de madeira. 180x220x220cm. 2017. Fonte: Acervo pessoal, Curitiba.

As ausências que vieram com as mortes de irmãos, pai, mãe, foram se fazendo presentes enquanto afetos compartilhados, despedidas, saudades e memórias. A cadeira em movimento e vazia, com o som repetitivo que produz, alude à distância, ao esquecimento, à velhice. As camisas penduradas, recortadas e vazias, com leveza e balanço, narram o que existiu e já não existe. $O$ vestido, inteiro e preenchido como um corpo, cuida de todos os outros e dialoga com eles. Materializo estas ausências com roupas e objetos que as representem, criando uma narrativa que conviva com as perdas, pessoais e universais.

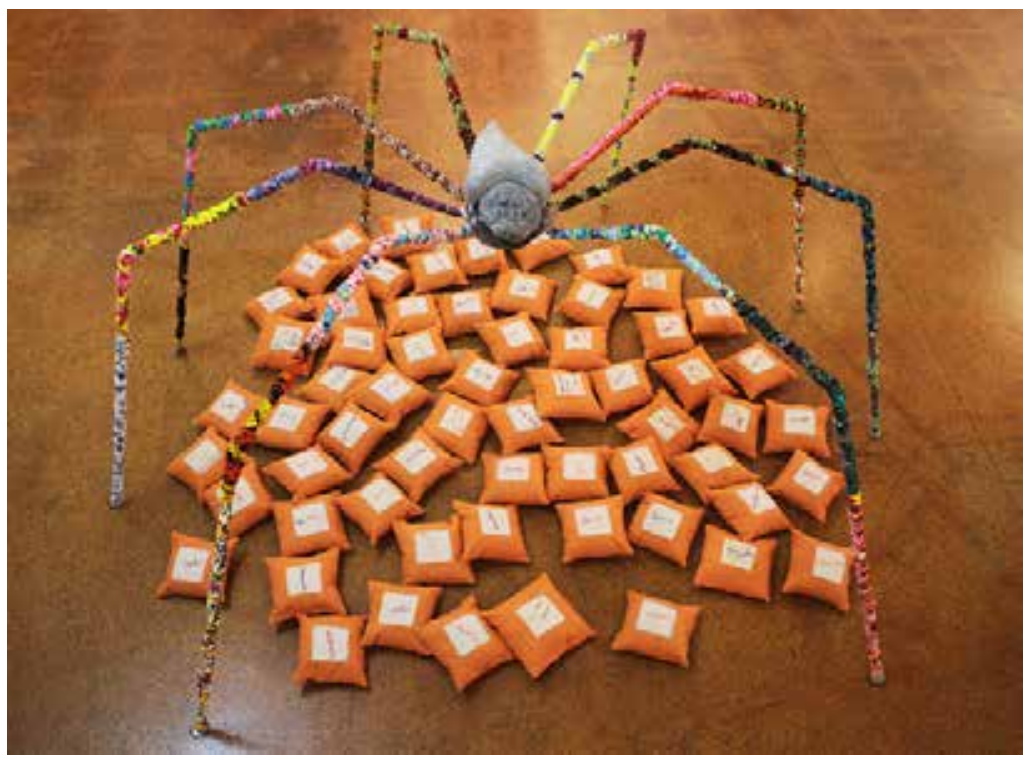

Fig. 3 - Tecelã de fios da memória, sob seu corpo abriga o ninho que te acolhe. Objeto escultórico, pedra sabão, ferro, tecido, almofadas de linho bordadas, 180x220x200 cm. 2017.

Fonte: Acervo pessoal, Curitiba. 
A aranha, enquanto representação da tecelã, acolhedora, criadora e contadora de histórias, surge na obra "Tecelã de fios da memória, sob seu corpo abriga o ninho que te acolhe". As pernas de ferro que sustentam o corpo de pedra sabão são revestidas de tecido, oferecendo maciez e suavidade ao metal. Os tecidos guardam em suas texturas a representação da pele, do toque, do afeto, proporcionam a leveza de um colo que abraça e aconchega. As almofadas de linho bordadas completam o acolhimento, 0 convite à experiência de descanso e alento. As palavras bordadas originaram-se de dois momentos distintos. No primeiro, surge a indignação com os acontecimentos recentes da história do país, recolho trechos de músicas de Chico Buarque de Holanda compostas no período da ditadura militar, bastante ouvidas e marcadas nos anos 1980, expressam discurso e reflexão conectados aos acontecimentos de 2016/2017. No segundo momento, intento imergir nas profundezas do inconsciente, buscando, pela associação livre, as palavras que lá se encontram. Escrevo a sequência encadeada e aparentemente desconexa, transferindo pelo bordado para o tecido, traduzindo as histórias guardadas que anseiam para serem contadas. Nesta obra, aspiro tecer um espaço onírico, teia de sonhos, demarcada pelas pernas da aranha, que cria um ninho, abriga, acolhe e protege.

Estas obras dialogam com a vida, surgem de vivências singulares que aos poucos formam uma imensa colcha tecida por fios e enlaces da memória com a intenção de compartilhar alumbramentos. Lembrando Galeano:

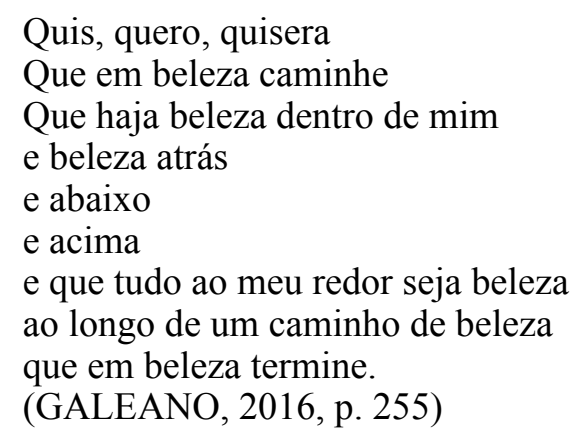

Tramando os vestígios do tempo, das ausências, da autobiografia, com os fios dos afetos, celebro o mistério dos encontros e restauro as pegadas da memória pelos caminhos da vida.

\section{Conclusão}

Esta pesquisa trouxe a discussão teórica e a construção de obras autorais, que, para além da singularidade do pesquisador, pode contribuir com outras pesquisas no campo da arte. Sem conclusões definitivas, encerro com indagações acerca de como diferentes obras, de diferentes artistas, podem evocar memórias, ausências e uma escrita de si, que extrapola os limites do particular e provoca o coletivo. Pela especificidade da pesquisa em arte, espero que a narrativa aqui construída, longe de alcançar unanimidade, provoque polêmicas e dissonâncias. Almejo que o artigo levante questões ao leitor, assim como as obras instiguem o observador.

Ao conectar-me às obras dos artistas de referência e trazer para os trabalhos questões similares, como as memórias, as ausências e a autobiografia, construo uma 
poética singular que dialoga com artistas consagrados na história da arte, de uma forma peculiar.

A discussão teórica, articulada às obras produzidas, aborda a materialização da memória. Bachelard fala que ao recordarmos, retornamos àquele lugar distante, que aproxima-se pela lembrança. Didi-Huberman discute a impressão que deixamos no mundo, que torna-se presença na própria pele, e ao mesmo tempo mostra os sinais das perdas, e a possibilidade de contato com o outro. Lejeune discorre sobre a fixação do tempo que realizamos na escrita de um diário, colecionando vestígios, marcas, pegadas, relíquias. Espero haver contemplado estas questões, tanto na escrita deste artigo quanto nas obras propostas.

\section{Referências}

BACHELARD, Gaston. O novo espírito científico: A poética do espaço (Os pensadores). São Paulo. Nova Cultural, 1988.

BOURGEOIS, Louise; BERNADAC, Marie-Laure; OBRIST, Hans-Ulrich. Louise Bourgeois, Destruição do pai, Reconstrução do pai. São Paulo: Cosac \& Naify Edições, 2000.

BOURGEOIS, Louise. Maman. 1999, Steel, $35 \mathrm{ft}$ in height, Tate Modern. Disponível em: http://louisebourgeois.yolasite.com/gallery.php>. Acesso em: 27 abril 2018

BOURGEOIS, Louise. Ode à l'oubli. 2002. Fabric illustrated book with 35 compositions: 32 fabric collages, 2 with ink additions, and 3 lithographs (including cover), page (each approx.): $113 / 4$ x 13" $(29.8$ x $33 \mathrm{~cm})$; overall: $11 \times 123 / 16$ x 1 3/4" (28 x $31 \times 4.5 \mathrm{~cm})$. Disponível em: <https://www.moma.org/explore/collection/lb/index>. Acesso em: 27 abril 2018

BOURGEOIS, Louise. The Destruction of the Father. 1974, Plaster, latex, wood, fabric and red light. Disponível em: <http://louisebourgeois.yolasite.com/gallery. php>. Acesso em: 27 abril 2018

BRANDÃO, Juanito de Souza. Mitologia Grega. Vol. II, Petrópolis, Vozes, 1987.

CHEVALIER, Jean; GHEERBRANT, Alain. Dicionário de Símbolos: (mitos, sonhos, costumes, gestos, formas, figuras,cores, números). Rio de Janeiro. José Olympio Editora. 11 a Edição. 1997.

DIDI-HUBERMAN, Georges. L'Empreinte. Catálogo de Exposição, 19 de fev.-19 mai. 1997, Paris, Centre Georges Pompidou. 1997 (Livre adaptação e tradução para o Mestrado de Artes Visuais da EBA-UFMG por Patrícia Franca-Huchet), 2000.

ESTÉS, Clarissa Pinkola. Mulheres que Correm com os Lobos: mitos e histórias do arquétipo da mulher selvagem. Rio de Janeiro. Rocco, 1994. 
FRANCA, Patrícia (Adapt. Trad.). L'Empreinte - Parte I e II. [s/l.: s.n., 2000] Inédito. Adaptação em português do original francês: DIDI-HUBERMAN, Georges (Org.). L'Empreinte. Paris: [s.n.], 1997. Catálogo de exposição, 19 fev. - 19 mai. 1997, Centre G. Pompidou.

FONTELA, Orides. Teia: poemas. São Paulo. Geração Editorial, 1996.

FREUD, Sigmund. Obras Completas. Tomo II. Madrid. Editorial Biblioteca Nueva, 1973.

GALEANO, Eduardo. Livro dos Abraços. Porto Alegre, L\&PM, 1991.

GALEANO, Eduardo. O caçador de histórias. Porto Alegre, L\&PM, 2016.

HERRERA, Hayden. Frida: uma biografia. São Paulo. Globo, 2011.

HOLLANDA, Chico Buarque. Album Paratodos, Nova York, RCA Records. 1993, música Futuros Amantes.

KAHLO, Frida. O diário de Frida Kahlo: um autorretrato íntimo. Rio de Janeiro. José Olympio, 1996.

KAHLO, Frida. El Abrazo de Amor del Universo, la Tierra (México), Diego,Yo y el Sr. Xolotl, 1949, Oleo sobre masonite / 70 x 60,5 cm / Colección J. y N. Gelman. Disponível em: <http://www.proa.org/exhibiciones/pasadas/mexico/salas/kahlo-04. html>. Acesso em: 27 abril 2018

KAHLO, Frida. La mesa herida, 1940. Óleo sobre lienzo, $122 \times 244 \mathrm{~cm}$. Disponível em: <https://i1.wp.com/www.revistazena.com.br/wp-content/uploads/2010/09/ 1940-la-mesa-herida.jpg >. Acesso em: 27 abril 2018

KAHLO, Frida. Las dos Fridas, 1939, óleo sobre lienzo, 173 x $173 \mathrm{~cm}$, Museo de Arte Moderno, Ciudad de México. Disponível em: <http://www. elcuadrodeldia.com/ post/99121299123>. Acesso em: 27 abril 2018

KAHLO, Frida. Mis abuelos, mis padres y yo. (Árbol genealógico), 1936. Oleo y tempera sobre metal. $30.7 \times 34.5 \mathrm{~cm}$. Museo de Arte Moderno, Nueva York. Disponível em: <http://lacasadefriducha.blogspot.com.br/2007/08/mis-abuelos-mis-padres-y-yo.html>. Acesso em: 27 abril 2018

LAGNADO, Lisette. Leonilson: são tantas verdades = so many are the truths. São Paulo, Projeto Leonilson e Sesi, 1995.

LARRAT-SMITH, Philip. Louise Bourgeois: o retorno do desejo proibido. São Paulo. Instituto Tomie Ohtake, 2011. 
LEJEUNE, Philippe. O pacto autobiográfico: De Rousseau à Internet. Belo Horizonte. Editora UFMG, 2014.

LEONILSON, José. Águas divididas, 1992. Bordado e costura, linha sobre seda estampada e tecido de algodão listrado $42 \times 38 \times 0 \mathrm{~cm}$. Disponível em: <http://www. projetoleonilson.com.br/obras.aspx>. Acesso em: 27 abril 2018

LEONILSON, José. Leonilson. Empty Man, de 1991. Bordado sobre tecido. 53 x $37 \mathrm{~cm}$. Coleção Particular. Disponível em: <http://hardecor.com.br/leonilson-na-pinacoteca-em-sp>. Acesso em: 27 abril 2018

LEONILSON, José. Ninguém, 1992. Bordado sobre algodão (fronha), Embroidery on cotton (pillowcase) $22 \times 43 \mathrm{~cm}$. Disponivel em: <http://www.iberecamargo.org. br/site/uploads/multimediaExposicao/260420124611_FIC_Leonilson_CATALOGO. pdf $>$. Acesso em: 27 abril 2018

MACHADO, Ana Maria. De Olho nas Penas. Rio de Janeiro. Salamandra. 1985.

MIYADA, Paulo. In: Frida Kahlo: conexão entre mulheres surrealistas no México. Curador Paulo Miyada, Agnaldo Farias. São Paulo. Instituto Tomie Ohtake, 2015.

PEDROSA, Adriano, in LAGNADO, Lisette. Leonilson: são tantas verdades = so many are the truths. São Paulo, Projeto Leonilson e Sesi, 1995.

PEDROSA, Adriano (edição e textos). Leonilson - Truth, Fiction. Catálogo. São Paulo: Pinacoteca do Estado/Cobogo Editora, 2014.

PESSOA, Fernando. Poesias Inéditas 1930-1931. Lisboa: Ática, 1990.

QUEIRÓS, Bartolomeu Campos. Por parte de pai. Belo Horizonte. RHJ, 1995.

REIS, Paulo. Uma História da Pele. in HERKENHOFF, Paulo; PEDROSA, Adriano (orgs). Marcas do corpo, dobras da alma. Curitiba. 2000.

REIS, Paulo Roberto de Oliveira. A construção do desenho: sujeito, temporalidade e cartografias em Leonilson. 1998. 88f. Dissertação (mestrado) - Pontificia Universidade Católica do Rio de Janeiro, Departamento de História.

REY, Sandra. in BRITES, Blanca; TESSLER, Elida (orgs). O meio como onto zero: metodologia da pesquisa em artes plásticas. Porto Alegre. Ed. Universidade/UFRGS, 2002.

SANT'ANNA, Affonso Romano de, 0 lado esquerdo do meu peito: (livro de aprendizagens). Rio de Janeiro, Rocco, 1992. 
WHITMAN, Walt. Folhas de Relva, Rio de Janeiro, Civilização Brasileira, 1964. 